\title{
The extraction of natural essential oils and terpenoids from plants by supercritical fluid
}

\author{
Hua Liu ${ }^{1,2, *}$ Ruixu Zhan ${ }^{1}$, Liangjian Wen ${ }^{1}$, Zhenyu Zhong ${ }^{1}$ \\ ${ }^{1}$ Guangzhou College of Technology and Business, 510850 Guangzhou, China \\ ${ }^{2}$ University Putra Malaysia, 43400 Serdang, Selangor, Malaysia
}

\begin{abstract}
In order to provide guidance for the improvement of supercritical fluid extraction technology in the extraction of natural volatile oil and terpenoids from plants, SFE was compared with steam distillation, solvent extraction, Soxhlet extraction, pressure method and other traditional extraction processes, and the supercritical $\mathrm{CO} 2$ extraction conditions of SFE in the extraction of natural volatile oil and terpenoids were studied, including temperature, pressure, extraction time, extraction time, extraction time, extraction time, extraction time, extraction time and so on. The influence of entrainer or co extractant on the extraction effect was discussed to provide optimization parameters for the extraction process of natural volatile oil and terpenoids. SFE technology has advantages in the extraction of natural plant volatile oil and has broad application prospects in industrial production.
\end{abstract}

\section{Introduction}

In recent years, the green separation and extraction technology for food processing has been favored, which makes a new green food separation technology supercritical fluid extraction become a research hotspot at home and abroad. Supercritical fluid has dual characteristics (high density and low viscosity) in supercritical state. It can be purposefully extracted from some natural substances and used to screen or remove some components in food. Compared with the traditional extraction process, it has the characteristics of high efficiency, environmental protection, energy saving and easy control.

Natural active ingredients such as essential oils, carotenoids, fatty acids, polyphenols and flavonoids are usually extracted by steam distillation, solvent extraction, Soxhlet extraction, pressure method and hydrodistillation, but there are some limitations, such as too much time-consuming, using too many organic solvents, losing some volatile compounds and degrading heat-resistant compounds, Toxic solvents may remain in the extract, resulting in low yield and low extraction efficiency. Therefore, a green extraction method SFE was developed to reduce the consumption of energy and solvent, reduce the processing time, and replace the conventional solvent with environmentally friendly substitutes. As a new extraction technology, SFE is a more environmentally friendly method, which can extract and separate natural bioactive substances from herbs, spices, aromatic plants and medicinal plants. In this paper, the effects of supercritical fluid extraction (SFE) on the extraction of natural essential oils and terpenoids from plants were discussed, and compared with traditional extraction methods such as steam distillation, solvent extraction, Soxhlet extraction and pressure method. The SFE conditions for the extraction of natural essential oils and terpenoids, alkaloids, phenols, saponins, polysaccharides, etc. were analyzed, including temperature, pressure, temperature, temperature and pressure The effects of entrainer or co extractant on the extraction efficiency were discussed, which could provide optimization parameters for the extraction process of natural volatile oil and terpenoids, and provide guidance for the improvement of supercritical fluid extraction technology in the extraction of plant natural active components.

\section{Supercritical fluid extraction technology}

\subsection{Characteristics of supercritical fluid extraction technology}

Supercritical fluid extraction technology has the characteristics of fast extraction speed, high efficiency, no pollution, good thermal sensitivity, etc. supercritical $\mathrm{CO} 2$ fluid extraction temperature is low, which can avoid the damage of some chemical substances. At the same time, the polarity of the extract is wide, including a large number of volatile and low polarity volatile components. Supercritical $\mathrm{CO} 2$ fluid extraction temperature is low, which can avoid the destruction of some chemical substances. Supercritical fluid extraction is widely used in $\mathrm{CO} 2$, ethylene, ethane, propylene, ammonia, water and other solvents. Ethylene, ethane and other solvents are harmful to human body, and are mainly used in industries other than food. Carbon dioxide is a non-toxic, harmless,

\footnotetext{
* Corresponding author: annylh2008@126.com
} 
non corrosive substance, which is easy to separate from compounds. At present, it is the most commonly used supercritical fluid extractant in the field of food.

\subsection{Extraction Parameters and influencing factors}

\subsubsection{Extraction temperature}

Temperature is the key parameter to control the extraction process of supercritical fluid extraction. With the increase of temperature, the thermal velocity of molecules increases, the probability of collision increases, and the solubility of carbon dioxide increases. With the increase of temperature, the density of carbon dioxide decreases and the ability to carry substances decreases. The extraction rate depends on which state is dominant at this temperature. Sometimes the higher the temperature, the lower the extraction efficiency. If the temperature changed from $80^{\circ} \mathrm{C}$ reduced to $50{ }^{\circ} \mathrm{C}$, the extraction rate of anthocyanins with $20 \mathrm{vol} \%$ ethanol was increased [1].

\subsubsection{Extraction pressure}

Pressure is also a key parameter to control the extraction process of supercritical extraction, and the extraction efficiency of supercritical extraction is mainly determined by the change of pressure. The solubility increases with the increase of pressure and extraction amount per unit time, but the pressure is not arbitrarily increased and selected. The increase of operating pressure should take into account the significant increase of equipment investment. In addition, when the pressure is relatively high, the content of pigment and other useless components in the extract will also increase, which has a certain impact on its quality. When the pressure rises to a certain point, the increment of pressure will be smaller and smaller. Wang Li et al. Proved that increasing the pressure from 150 bar to 300 bar means that the oil yield is increased by $53 \%$.

\subsubsection{Extraction time}

Extraction time also plays an important role in SFE, because extraction time has an important influence on substances. Short extraction time may lead to incomplete extraction, although with the increase of extraction time, more substances will be extracted; But after a certain time point, the change of extraction rate will be less and less obvious. Moreover, the extension of extraction time is at the cost of power, pressure and equipment loss. Although the extraction time is determined by the supercritical fluid flow rate, if the fluid flow rate is too fast, the extraction effect will also be affected. Therefore, the extraction time needs preliminary study to obtain the highest extract in the best time.

\subsection{4. $\mathrm{CO} 2$ flow}

The flow rate of carbon dioxide has a great influence on the extraction effect. As a double-edged sword, increasing the flow rate of $\mathrm{CO} 2$ can accelerate the flow of solvent and solute, which is convenient for extraction, at the same time, reducing the contact area of solvent and solute, which is not conducive to extraction.

\subsubsection{Entrainer}

Entrainer refers to a small amount of miscible volatile substances added in supercritical fluid gas between separated substances and supercritical components. It is often used to improve or maintain the selectivity of extracted solutes and increase the solubility of volatile compounds. When Sainz Martinez aitor et al. Extracted anthocyanins and iridoids from haskop berry powder, all SCCO2 parameters were kept constant, and the ethanol concentration was $80^{\circ}$ It was found that the yield of $20 \%$ ethanol was the highest in the range of 0 to $20 \mathrm{vol} \%$ under the pressure of $30 \mathrm{MPa}$ and $\mathrm{C}$ [2].

\subsection{Comparison of supercritical fluid extraction and other extraction technologies}

Bioactive compounds are usually extracted by steam distillation, solvent extraction, Soxhlet extraction, pressurized extraction and hydrogenated distillation, but there are some limitations. Different from supercritical fluid extraction, these technologies use other organic solvents except water and ethanol, which will lead to harmful solvent residues and low extraction efficiency[3-5]. Compared with most traditional extraction methods, supercritical fluid extraction technology has the advantages of higher efficiency, more environmental protection, more energy saving and easy control, as shown in Table 1.

Table 1 Comparison of supercritical extraction technology with other extraction technologies

\begin{tabular}{|c|l|l|l|l|l|l|}
\hline Condition & \multicolumn{1}{|c|}{ SD } & \multicolumn{1}{|c|}{$\begin{array}{c}\text { Soxhlet } \\
\text { extraction }\end{array}$} & \multicolumn{1}{|c|}{ UAE } & MAE & PLE & SFE \\
\hline Solvents & water & $\begin{array}{l}\text { Anhydrous } \\
\text { ether, water }\end{array}$ & $\begin{array}{l}\text { Anhydrous } \\
\text { ether, water }\end{array}$ & $\begin{array}{l}\text { Hexane, water, } \\
\text { dichloromethan } \\
\text { e, acetone, } \\
\text { ethanol }\end{array}$ & $\begin{array}{l}\text { Anhydrous } \\
\text { ethanol, ethanol } \\
\text { water solution }\end{array}$ & $\begin{array}{l}\text { Supercritical } \\
\text { carbon dioxide, } \\
\text { ethanol, } \\
\text { methanol }\end{array}$ \\
\hline $\begin{array}{c}\text { Temperature } \\
\text { range }\end{array}$ & About $100^{\circ} \mathrm{C}$ & $95^{\circ} \mathrm{C}-105^{\circ} \mathrm{C}$ & $10-70{ }^{\circ} \mathrm{C}$ & $80-350^{\circ} \mathrm{C}$ & $50-200{ }^{\circ} \mathrm{C}$ & $30-100{ }^{\circ} \mathrm{C}$ \\
\hline
\end{tabular}




\begin{tabular}{|c|c|c|c|c|c|c|}
\hline $\begin{array}{c}\text { Time } \\
\text { consuming }\end{array}$ & $>4 \mathrm{~h}$ & $6-12 \mathrm{~h}$ & $10-90 \mathrm{~min}$ & $3-30 \mathrm{~min}$ & $<1 \mathrm{~h}$ & $10-90 \mathrm{~min}$ \\
\hline Advantage & $\begin{array}{l}\text { Suitable for } \\
\text { volatile, not } \\
\text { destroyed by } \\
\text { steam, stable in } \\
\text { water }\end{array}$ & $\begin{array}{l}\text { Good } \\
\text { selectivity, low } \\
\text { energy } \\
\text { consumption, } \\
\text { simple } \\
\text { equipment and } \\
\text { easy operation }\end{array}$ & $\begin{array}{l}\text { No heating, less } \\
\text { solvent, high } \\
\text { extraction } \\
\text { efficiency, short } \\
\text { extraction time } \\
\text { and simple } \\
\text { operation }\end{array}$ & $\begin{array}{l}\text { Fast and } \\
\text { efficient, } \\
\text { uniform } \\
\text { heating, good } \\
\text { selectivity, less } \\
\text { solvent } \\
\text { consumption }\end{array}$ & $\begin{array}{l}\text { The method has } \\
\text { the advantages } \\
\text { of small amount } \\
\text { of organic } \\
\text { solvent, high } \\
\text { recovery rate } \\
\text { and good } \\
\text { reproducibility }\end{array}$ & $\begin{array}{l}\text { High efficiency, } \\
\text { environmental } \\
\text { protection, } \\
\text { energy saving } \\
\text { and easy to } \\
\text { control }\end{array}$ \\
\hline Shortcoming & $\begin{array}{l}\text { Need to be } \\
\text { heated, not } \\
\text { suitable for the } \\
\text { extraction of } \\
\text { chemical } \\
\text { unstable } \\
\text { components }\end{array}$ & $\begin{array}{l}\text { taking a long } \\
\text { time }\end{array}$ & $\begin{array}{l}\text { restricted by } \\
\text { ultrasonic } \\
\text { attenuation }\end{array}$ & $\begin{array}{l}\text { can destroy } \\
\text { organic matter }\end{array}$ & $\begin{array}{l}\text { The use of } \\
\text { organic solvents } \\
\text { is toxic to the } \\
\text { environment }\end{array}$ & $\begin{array}{l}\text { difficult to } \\
\text { dissolve high } \\
\text { molecular } \\
\text { weight } \\
\text { compounds }\end{array}$ \\
\hline $\begin{array}{l}\text { Scope of } \\
\text { application }\end{array}$ & $\begin{array}{l}\text { volatile, not } \\
\text { destroyed by } \\
\text { steam and } \\
\text { stable in water }\end{array}$ & Lipids & $\begin{array}{l}\text { widely used in } \\
\text { the extraction } \\
\text { of most } \\
\text { effective } \\
\text { components }\end{array}$ & $\begin{array}{l}\text { Suitable for } \\
\text { thermally } \\
\text { unstable } \\
\text { materials }\end{array}$ & Volatile matter & $\begin{array}{l}\text { widely used in } \\
\text { the extraction } \\
\text { of most } \\
\text { effective } \\
\text { components }\end{array}$ \\
\hline
\end{tabular}

\section{Extraction of essential oils and terpenoids from natural plants by supercritical fluid}

The SFE extraction conditions of natural plant volatile oil and terpenoids were studied, including temperature, pressure, extraction time and flow rate of dioxide.

\subsection{Physical and chemical properties of volatile oils and terpenes}

Volatile oil, also known as essential oil, is a kind of oily liquid with aromatic smell, rich in terpenoids. Because of its small molecular weight and low boiling point, it can volatilize at room temperature, and can be distilled with steam. The volatile oil is often extracted by steam distillation, but the operation is complex, the extraction efficiency is low, the time is long, and the steam distillation has a certain degree of damage and decomposition to its effective components. Terpenoids are hydrocarbons and their oxygen-containing derivatives that exist in nature. They have multiple isoprene units and are the main components of some plant spices, resins and pigments.

\subsection{Extraction conditions}

Supercritical CO2 extraction technology has low operating temperature, good selectivity, and $\mathrm{CO} 2$ is non-toxic, cheap and other characteristics. Taking Zanthoxylum bungeanum seed as raw material, supercritical CO extraction technology has made a lot of research. Sun Rui, Zhang Yonghan and others used response surface method to analyze the oil extraction rate and the yield $\alpha$ - The extraction process of linolenic acid was optimized at the same time. The optimum conditions were as follows: pressure $30 \mathrm{MPa}$, temperature $51{ }^{\circ} \mathrm{C}$, time $90 \mathrm{~min}$. under the optimum conditions, the oil extraction rate of Zanthoxylum bungeanum seed was $12.52 \%, \alpha$ - The content of linolenic acid was $4.45 \%$.[6] Dong Zhenshan, Zhang Xinmin et al. Used supercritical $\mathrm{CO} 2$ extraction device to extract the tar. The best extraction conditions were obtained as follows: extraction pressure $35 \mathrm{MPa}$, extraction temperature $35^{\circ} \mathrm{C}$, $\mathrm{CO} 2$ flow rate $20 \mathrm{Lgh}$, extraction time $2.0 \mathrm{~h} .70$ components were detected, including 31 hydrocarbons, 14 esters, 9 ketones and 8 alcohols.[7] In addition, Zhou Feng and Bing Conanga et al. Extract the essential oil of sandalwood. [8]Duan Liping,[sun Weiwei, et al. Used response method to optimize supercritical fluid extraction of Dioscorea opposita oil.[9] Tian Yuan, sun Yufeng. Optimization of supercritical fluid extraction of essential oil from hemp leaves by response surface methodology.[10-13] Lanyansu, Xu Yuting et al. Used supercritical $\mathrm{CO} 2$ to extract volatile oil from fig leaves and isolated and identified 68 compounds. Duan Lei, Yu Huapeng, et al. Used response surface methodology to optimize supercritical $\mathrm{CO} 2$ extraction of Cyperus oleifera oil. [14-16]

\subsection{Influence of entrainer or co extractant on extraction efficiency}

Volatile oil and terpenoids can be volatilized at room temperature due to their small molecular weight and low boiling point [17-19]. According to the characteristics and functions of entrainer or coextraction agent, it can be known that the effect of entrainer and coextraction agent on the extraction efficiency of volatile oil and terpenoids by supercritical fluid extraction is relatively small[20-22].

Supercritical Fluid Extraction of natural essential oils and terpenoids from plants is showed in Table 2. 
Table 2 Supercritical Fluid Extraction of natural essential oils and terpenoids from plants

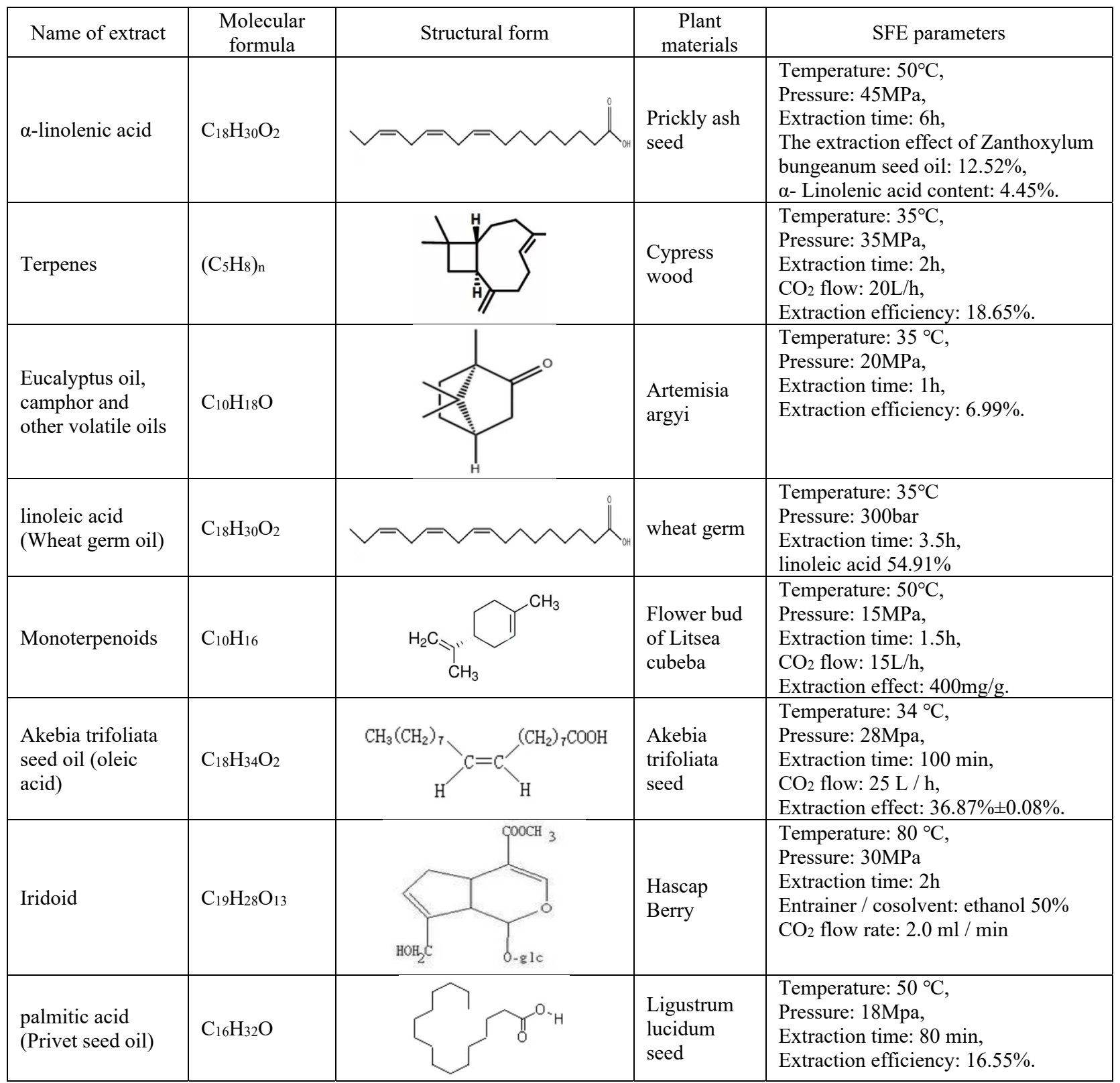

\section{Conclusion}

As a new green extraction method, supercritical fluid extraction (SFE) is widely used in food, medicine, biology and other fields. Supercritical fluid extraction also has its limitations, such as $\mathrm{CO} 2$ is difficult to dissolve high molecular weight compounds, such as carotenoids, triacylglycerides and so on. In the case of increasingly complex competition in the food industry, supercritical fluid extraction technology should be combined with other extraction technologies to obtain more effective extraction and purification methods, and make the process parameters meet the requirements of industrial production. Supercritical $\mathrm{CO} 2$ can be combined with mass spectrometry and spectroscopy, such as Fourier transform infrared spectroscopy combined with gas chromatography, atomic absorption spectrometry and fluorescence spectroscopy combined with the comprehensive utilization of supercritical CO2[26-28]. From the perspective of industrial production of essential oil, supercritical $\mathrm{CO} 2$ extraction is an efficient extraction method. Compared with other methods, $\mathrm{CO} 2$ is low cost, easy to obtain, non-toxic and tasteless, and the extracted essential oil does not contain impurities. Supercritical CO2 fluid has a strong attraction and wide application prospect in the industrial production of non polluting and high safety essential oil.

\section{Acknowledgments}

This work was supported by the (Key) Project of Department of Education of Guangdong Province (No2018ktscx270); Construction and management of laboratory (training room) in Guangzhou College of 
Technology and Business in 2019(Research on the construction of safety evaluation system of food testing laboratory for application oriented Undergraduate).

\section{Reference}

1. Sainz Martinez Aitor et al. LWT, 2021, 138 : 110633-.

2. S Martinez Aitor et al.LWT, 2021, 138 : 110633-.

3. R Yessica Estefany,M Fernando Carlos. J Food Pro.Engin., 2021, 44(4)

4. Jafarian Asl P, Niazmand R, Yahyavi F.2020 Mar $25 ; 6(3)$

5. Chaoyi Z.; Zhilong Z.; Jincheng Z.; Guirong Z.[J]. Chin.Cond, 2021, 46 (03): 157-161.

6. Rui S.; Yonghan Z.; Xianwei L.; Jie S.; Xiulan G.; [J]. Chin.Cond, 2021, 46 (01): 51-56.

7. Zhenshan D.; Xinmin Z.; Deyu L.; Huaiyuan N.; Yongming X. [J]. Chem. R, 2021 , 43 (03): 335-338.

8. Feng Z.; Pingzuonanga, Gu Z.; Ma B.; Zengpingcuo S.; Gesang Rob.[J].Chin. H New Technol., 2020 (22): 150-152

9. Liping D.; Weiwei S.; Hao C.; Xiangle C.; Chao X.; Sheng C.F.Iy, 2020, 41 (11): 58-61.

10. Yuan T.; Yufeng S.; Zhenghai Z.; Xu Z.; Yu S.;Baochang G.F.ISci.Technol.: 1-8 [2021-03-28]

11. Yansu L.; Yuting X.; Le Z.; Ningtao H.; Weihui C.J Huangshan U, 2020, 22 (05): 47-50.

12. Lei D.; Huapeng Y.; Mo H.; Shan C.; Xiuli W.F.I, 2020. 41 (09): 118-121.

13. C Carrera, S.; Tramo., D.P.; Cruz, A.B.; Cruz, R.C.B.; Müller, J.M.; Hense, H. J. Supercrit. Fluids 2019, 152, 1-9.

14. RYessica Estefany,M Fernando Carlos. J.Food Pro.Engin. 2021, 44(4)

15. Zhong Y.; Guiyun Z.; Liping Z.; Zhen L.; Qiaolan F.SMA, 202048 (07): 1135-1139.

16. P Moral, S.; Borrás-Linares, I.; Lozano-Sánchez, J.; Arráez-Román, D.; Martínez-Férez, A. J. Supercrit. Fluids 2018, 147, 213-221.

17. Shuangqi T, Yue S, Zhicheng C, J.Food Quality, vol. 2021, A. 9 pages, 2021.

18. L Thao My Phan, K Thien Phuc Nguyen, H Thanh Vuong, Do Dat Tran, Tran Xuan Phuong Nguyen, J.Chem., vol. 2020, Article ID

19. S Martinez Aitor et al.LWT, 2021, 138 : 110633-.

20. Tramontin, D., Cadena-Carrera, S.E., Assreuy, J. et al.J Food Sci Technol (2021).

21. Lanfang T.; Wenzhen X.; Yuege Y.; Fanqin M.Chem. Management, 2021 (06): 81-82.

22. Jafarian Asl P, Niazmand R, Yahyavi F Heliyon. 2020 Mar 25;6(3)

23. Xuefeng Y.;Hailong H. ; Junting S.; Xiuxue L.;G Chem. , 2020,(23):55-57.
24. Qing W.; Chao L.; Xinkun W.; Tongcheng X.;Xu G.F.I,2019,40(12):85-88

25. Qizhao L.; Qiang W.;J H.Univ.Sci. Technol., 2020,22(05):71-76.

26. Weiye L.; Haishun W.; Huazhong Y.;[J/OL].Food I.D

27. Zixian Z.; [D].Z.Unive. ,2020.

28. Xiaoqiang D.; Shuqing J.; Lili Li J.; Bolun F.; Baoxin C.;J].C.R.M,2020,27(16):47-48. 